\title{
Editorial
}

Journal of Innate

Immunity
J Innate Immun 2009;1:395-396

DOI: $\underline{10.1159 / 000226246}$

Published online: June 24, 2009

\section{Innate Immunity in Viral Infections}

In late April, 2009, an unanticipated influenza A/ H1N1 virus appeared in Mexico and has rapidly spread at least 10 countries (as of April 28, 2009) by virtue of air travel. Through networks of national and international health surveillance agencies, this virus was rapidly identified as of porcine origin and has been dubbed 'Swine flu' by the media. Concerns have been raised that this virus may lead to a pandemic, and some predictions include severe disease comparable to the 1918 A/H1N1 'Spanish flu', which may have killed 100 million people worldwide. The worst-case scenario which has been put forward has alarmed many people. This stress, in addition to the worldwide financial recession, may lead to additional susceptibilities to illnesses (and potentially more severe infections), including viruses, due to the impact of stress on both the innate and adaptive immune response.

It has been my pleasure to join the Editorial Board of the recently launched Journal of Innate Immunity. One of the obligations of Editorial Board membership is the far from onerous responsibility of organizing a special focus section of complementary manuscripts which have been submitted in the usual investigator-initiated stream. The Journal of Innate Immunity is a peer-reviewed journal entirely devoted to this critically important and often overlooked field of immunology. The innate immune response is essential when the host encounters a pathogen, such as a viral infection. Many papers which were invited will appear in forthcoming issues, due to page constraints. All of these outstanding papers have undergone rigorous peer review.

The first review of this special focus section has been contributed by Ronald Harty, Paula Pitha and Atsushi Okumura [1] on a recently-noted antiviral pathway which is dependent on the ying-yang of enzymes, which alter- natively adds the ubiquitin-like protein IFN-stimulated gene 15 (ISG15) or removes it from proteins. They have found that the ISGylation of Nedd4 (an E3 ubiquitin-ligase) impairs the ability of Ebola virus VP40 and other viral matrix proteins to initiate assembly and budding. Targeting the mono-ubiquitination of viral matrix proteins may be a future therapeutic target.

Post-translational modification of proteins can take many forms, including phosphorylation, isoprenylation and glycosylation. In their minireview, Kristin Rogers and Mark Heise [2] discuss the role of oligosaccharide modification of viral proteins in determining host cell tropism and innate responses. This is important, as has been shown for influenza spread between avian, porcine and human species. The minireview covers the very important role of glycosylation of viral receptors for Flaviviruses (Dengue, West Nile) and Alphaviruses (Venezuelan and other equine encephalitis viruses) in these pathogens' life-cycles, in which they move from arthropod to mammalian species .

Defensins are a family of closely related proteins, which have been previously shown to contribute to antibacterial responses. Jian Ding, Yi-Ying Chou and Theresa Chang [3] discuss the early contribution of defensins to antiviral immunity. They document the role in innate host responses to infections of a wide range of viruses, including HIV, herpes simplex, influenza A, respiratory syncytial virus, parainfluenza, vaccinia, vesicular stomatitis, cytomegalovirus, BK virus, adenovirus and papilloma.

Viruses not only cause acute, latent or chronic infections, some virus infections may lead to the development of autoimmunity in hosts. Martin Richer and Marc Horwitz [4] examine the critical role of early innate respons-

\section{KARGER}

Fax +4161306 1234

E-Mail karger@karger.ch

www.karger.com (c) 2009 S. Karger AG, Basel

1662-811X/09/0015-0395\$26.00/0

Accessible online at: www.karger.com/jin 
es in determining whether the host ultimately develops myocarditis or type I diabetes following coxsackievirus infection.

The last review in this section comes from Stephane Daffis, Mehul Suthar, Michael Gale Jr. and Michael Diamond [5]. They examine the essential antiviral interferon pathway and the evasive responses of the arthropodborne West Nile virus in infections of mammals. The complexity of the induction of IFN (helicases, Toll-like receptors) and the responses of distinct cell types are illustrated in an excellent figure.

We have also included one research article, from Marco Hoffmann and colleagues [6], on a new evasive mechanism by which hepatitis $C$ virus is able to outwit the cell autonomous innate immune response. They have identified interference by the viral envelope in binding of the viral core protein to the cell surface Toll-like receptor 2 molecule. Thus the viral envelope impedes early host warning by IFN production.

Carol Shoshkes Reiss, New York, N.Y., USA
1 Harty RN, Pitha PM, Okumura A: Antiviral activity of innate immune protein ISG15. J Innate Immun 2009;1:397-404.

2 Rogers KM, Heise M: Modulation of cellular tropism and innate antiviral response by viral glycans. J Innate Immun 2009;1:405412

3 Ding J, Chou Y-Y, Chang TL: Defensins in viral infections. J Innate Immun 2009;1:413420

4 Richer MJ, Horwitz MS: The innate immune response: an important partner in shaping coxsackievirus-mediated autoimmunity. J Innate Immun 2009;1:421-434.

5 Daffis S, Suthar MS, Gale M, Diamond MS Measure and countermeasure: type I IFN $(\mathrm{IFN}-\alpha / \beta)$ antiviral response against West Nile virus. J Innate Immun 2009;1:435445.

6 Hoffmann M, Zeisel MB, Jilg N, ParanhosBaccalà G, Stoll-Keller F, Wakita T, Hafkemeyer P, Blum HE, Barth H, Henneke P, Baumert TF: Toll-like receptor 2 senses hepatitis $\mathrm{C}$ virus core protein but not infectious viral particles. J Innate Immun 2009;1:446-454. 